\title{
Outcome of paediatric cataract surgery in Northwest Ethiopia: a retrospective case series
}

\author{
Mulusew Asferaw, ${ }^{1}$ Sisay Yoseph Mekonen, ${ }^{1}$ Geoffrey Woodruff, ${ }^{2}$ Clare E Gilbert, ${ }^{3}$ \\ Samson Tesfaye ${ }^{4}$
}

'Department of Ophthalmology, University of Gondar, Gondar, Ethiopia

${ }^{2}$ Department of Ophthalmology, University of Leicester, Leicester, UK

${ }^{3}$ Clinical Research Department, International Centre for Eye Health, London School of Hygiene and Tropical Medicine, London, UK

${ }^{4}$ Orbis International-Ethiopia, Addis Ababa, Ethiopia

\section{Correspondence to}

Dr Mulusew Asferaw,

Department of Ophthalmology, University of Gondar, Gondar, Ethiopia; muasf@yahoo.com

Received 25 October 2017 Revised 6 March 2018 Accepted 12 March 2018 Published Online First 18 April 2018

Check for updates

To cite: Asferaw M, Mekonen SY, Woodruff G et al. Br J Ophthalmol 2019;103:112-118.

\section{ABSTRACT}

Aim To assess visual acuity outcomes, and factors associated with the outcome, of paediatric cataract surgery at the Child Eye Health Tertiary Facility, Gondar, Northwest Ethiopia.

Methods The medical records of children aged below 16 years who underwent cataract surgery between September 2010 and August 2014 were reviewed for preoperative, surgical and postoperative data.

Results One hundred and seventy-six eyes of 142 children (mean age 7.9 years \pm 4.2 SD, 66\% male) who had cataract surgery were included. Twenty-five per cent (35/142) of children had bilateral cataract, $18(13 \%)$ had unilateral non-traumatic cataracts and $89(63 \%)$ had unilateral traumatic cataracts. An intraocular lens was implanted in $93 \%$ of eyes. Visual acuities at last follow-up: bilateral cases in the better eye: good ( $\geq 6 / 18$ or fix and follow) in $21 / 34$ eyes $(62 \%)$, borderline $(<6 / 18-6 / 60)$ in 4 eyes $(12 \%)$ and poor $(<6 / 60)$ in 9 eyes $(26 \%)$. In unilateral nontraumatic cases: good in 6 eyes $(33 \%)$, borderline in 3 eyes $(17 \%)$ and poor in 9 eyes $(50 \%)$. In unilateral traumatic cases: good in 36 eyes $(40 \%)$, borderline in 20 eyes (23\%) and poor in 33 eyes (37\%). In bilateral cataract, worse outcomes were associated with preoperative nystagmus/strabismus. In traumatic cases, worse outcomes were associated with the preoperative trauma-related complications.

Conclusions Visual acuity improved significantly after surgery, with better outcomes in bilateral cases. Early detection and surgery by a trained surgeon with good follow-up and postoperative rehabilitation can lead to better visual outcomes.

\section{INTRODUCTION}

Up to a third of blindness in children in sub-Saharan Africa is due to congenital or developmental cataract, with approximately 19000 new cases each year. ${ }^{1}$ With the reduction of corneal blindness associated with measles and vitamin A deficiency, cataract is becoming an increasingly important cause of avoidable blindness in children in low-income settings. Well-documented challenges in achieving good outcomes after surgery in Africa are late presentation, surgical complications, poor follow-up for refractive correction and management of visual axis opacification. In some regions, there are gender differences in access. ${ }^{2}$ However, good results can be achieved by early meticulous surgery with aggressive management of the posterior capsule, intensive treatment of postoperative uveitis and good visual rehabilitation and follow-up. ${ }^{34}$

The prevalence of blindness in children in Ethiopia is estimated to be approximately 1 in 1000 children. ${ }^{5}$ Cataract accounted for $10 \%{ }^{67}$ of the causes of blindness in two studies from Ethiopian schools for the blind, while a population-based key informant study found cataract to be the most common cause of blindness (33\%) in Southern Ethiopia. ${ }^{8}$ Only a few studies have reported visual acuity (VA) outcomes in children following cataract surgery in Africa, ${ }^{9-14}$ with only one study of 73 cases from Ethiopia. ${ }^{15}$

The World Health Organization (WHO) recommends that paediatric cataract surgery be undertaken in tertiary-level eye care facilities with one facility per 10 million population. With support from Orbis International, Gondar University Hospital established a tertiary paediatric eye unit in 2012 with a trained paediatric ophthalmologist and support team. The purpose of this study was to assess the outcome of paediatric cataract surgery at this centre. The findings will guide improvements in the management of paediatric cataract in the region and more widely.

\section{PATIENTS AND METHODS Study setting}

The study was conducted at the University of Gondar Referral Hospital, Northwest Ethiopia, which is the only tertiary eye care and referral centre for an estimated population of 20 million, almost half of whom are children. Before 2012, the standard paediatric cataract surgical procedure was extracapsular cataract extraction, mainly in the form of manual small incision cataract surgery without primary posterior capsulotomy (PPC), performed by senior non-paediatric ophthalmologists. Since 2012, the currently recommended paediatric cataract surgery of lens aspiration with PPC and anterior vitrectomy $(\mathrm{AV})^{16}$ has been performed by an ophthalmologist trained in paediatric ophthalmology. Biometry has been performed routinely. Subconjunctival steroids are given to all eyes at the end of surgery. Cataract surgery is usually performed under general anaesthesia, with local anaesthesia for older cooperative children. Most bilateral cases have both eyes operated under general anaesthesia at the same session following strict procedures (ie, new surgical set and rescrubbing between eyes). This approach is adopted to reduce the risk of a second anaesthesia, to ensure that second eyes are 
operated on without delay and to reduce costs for parents. Children are usually seen on day 1 (at discharge), and at 1 week and 1 month after surgery.

\section{Study design: retrospective case series}

All children aged $0-15$ years undergoing cataract surgery between September 2010 and August 2014 were identified from the operating theatre logbook and their medical records were reviewed for demographic, preoperative, intraoperative and postoperative information by the principal investigator (MA, a paediatric ophthalmologist).

Preoperative data included address, age at surgery, gender, preoperative VA and the method of measurement, type and laterality of cataract, interval between the recognition of cataract by the parents and admission to hospital for surgery, the presence of ocular and systemic comorbidities, and method of intraocular lens (IOL) power calculation. Surgical data included date of surgery, surgical technique and method of anaesthesia. Details of the surgical techniques included method of anterior capsulotomy, whether PPC and AV were performed, whether an IOL was inserted and site of placement, intraoperative complications and surgeon profile. Postoperative complications and interventions, duration and total number of follow-up visits and presenting VA at the last visit were also documented.

\section{Definitions}

Visual outcomes are reported as presenting VA measured at the last postoperative follow-up visit and defined as good (VA $\geq 6 / 18$ or fix and follow (FF)), borderline (VA $<6 / 18-6 / 60$ ) or poor outcome (VA $<6 / 60$ or poor fixation pattern). We defined congenital cataract as a cataract manifested in the first year of life. Developmental cataract was defined as cataract that developed after the first year of life. Postoperative complications which occurred within 4 weeks of surgery were defined as early, and complications after 4 weeks were defined as late.

\section{Data analysis}

Data were entered into Epi Info V.3.3.2, and exported into SPSS V.16 for analysis. Multivariate binary logistic regression analysis was undertaken to determine predictors of postoperative VA outcomes for bilateral and traumatic cases separately. Unilateral non-traumatic cases were not included in the regression analysis because of the small number in this group. Visual outcome was defined as a dichotomous variable: good/borderline outcome (VA $\geq 6 / 60$ or $F F$ ) or poor outcome (VA $<6 / 60$ ). In bilateral cases, analysis was based on the VA outcome in the better seeing eye. One child who had only one eye operated was excluded from this analysis. Variables included for multivariate regression analysis for both groups (bilateral and traumatic cataract groups) were only those with $\mathrm{p}$ value $<0.2$ in univariate analysis, and all variables with $\mathrm{p}$ value $<0.2$ were entered simultaneously. A p value $<0.05$ was considered statistically significant.

\section{RESULTS}

A total of 160 children with cataract were operated over the 4-year period. Complete data were available for 142 $(89 \%)$ children of whom 35 (25\%) had bilateral cataract, 18 had non-traumatic unilateral cataract and 89 had unilateral traumatic cataract. The mean age at surgery was 7.9 (range $0.2-15$ ) years. Children having surgery for bilateral cataracts
Table 1 Demographic characteristics of children with cataract ( $n=142$ children)

\begin{tabular}{|c|c|c|c|}
\hline & $\begin{array}{l}\text { Bilateral } \\
(n=35), n(\%)\end{array}$ & $\begin{array}{l}\text { Unilateral non- } \\
\text { traumatic } \\
(n=18), n(\%)\end{array}$ & $\begin{array}{l}\text { Unilateral } \\
\text { traumatic } \\
(\mathrm{n}=89), \mathrm{n}(\%)\end{array}$ \\
\hline \multicolumn{4}{|c|}{ Age at surgery (year) } \\
\hline$<5$ & $17(48.6)$ & $6(33.3)$ & $2(2.2)$ \\
\hline $5-10$ & $10(28.6)$ & $10(55.6)$ & $49(55.1)$ \\
\hline $11-15$ & $8(22.8)$ & $2(11.1)$ & $38(42.7)$ \\
\hline \multicolumn{4}{|l|}{ Sex } \\
\hline Male & $20(57.1)$ & $11(61.1)$ & $63(70.8)$ \\
\hline Female & $15(42.9)$ & $7(38.9)$ & $26(29.2)$ \\
\hline \multicolumn{4}{|c|}{ Address by region } \\
\hline Amhara & $32(91.4)$ & $15(83.3)$ & 87 (97.6) \\
\hline Tigray & $1(2.8)$ & $3(16.7)$ & $2(2.2)$ \\
\hline Others* & $2(5.7)$ & - & - \\
\hline \multicolumn{4}{|c|}{ Approximate distance from hospital } \\
\hline$\leq 100 \mathrm{~km}$ & $18(51.4)$ & $6(33.3)$ & $39(43.8)$ \\
\hline$>100 \mathrm{~km}$ & $17(48.6)$ & $12(66.7)$ & $50(56.2)$ \\
\hline
\end{tabular}

*Southern nations, nationalities and people region (1), Benishangul-Gumuz (1).

were younger (mean 5.8, range 0.3-15 years) than the other two groups: unilateral non-traumatic cases (mean 7.0, range 0.2-14 years) and traumatic cases (mean 9.8, range 4-15 years). There was a preponderance of boys (66\%) over girls, particularly for traumatic cataract $(71 \%)$. The children were referred from 41 districts of the four regional states. The majority of children (94\%) came from Amhara regional state and most (56\%) lived more than $100 \mathrm{~km}$ from the hospital (table 1).

VA was assessed using Snellen acuity charts, Cardiff cards, LEA symbols and by assessing the fixation pattern in younger children. Among 176 eyes which had surgery, it was possible to record Snellen VA in 142 (81\%) eyes preoperatively and in $148(84.1 \%)$ eyes postoperatively. Before surgery, 13 of the 34 better seeing eyes of bilateral cases could fix and follow ( 7 eyes), had poor fixation (6 eyes) or acuity was not recorded (1 eye); after surgery, 12 of these eyes could fix and follow. Among the 18 eyes with unilateral non-traumatic cataract, four had poor fixation before surgery; after surgery, one eye had poor fixation and two could fix and follow. Among the 89 traumatic cases in two the VA was not recorded preoperatively; after surgery, one eye could fix and follow. Best corrected VA was not recorded in the medical records for 73 (41.5\%) eyes. Overall, among the eyes recorded with Snellen VA, before surgery $5 / 142$ eyes $(4 \%)$ had a presenting VA of 6/6-6/18 and 131 (92\%) had <6/60. Postoperatively, 55/148 eyes (37\%) had a presenting VA of 6/6-6/18 and 64 (43\%) had $<6 / 60$.

For each type of cataract the proportion of children with a presenting VA of $<3 / 60$ after surgery was lower than the proportion before surgery (figure 1 ). The proportion with a VA 6/6-6/18 or FF increased following surgery in all types of cataract, with better outcomes in bilateral cases compared with the other types (58\% bilateral; 40\% traumatic; 33\% unilateral non-traumatic).

\section{Bilateral cataract}

Sixty-nine eyes of 35 children with bilateral cataract were operated; one child had surgery to only one eye. Most bilateral cases $(86 \%, 30 / 35$ children) were operated at a single session. 


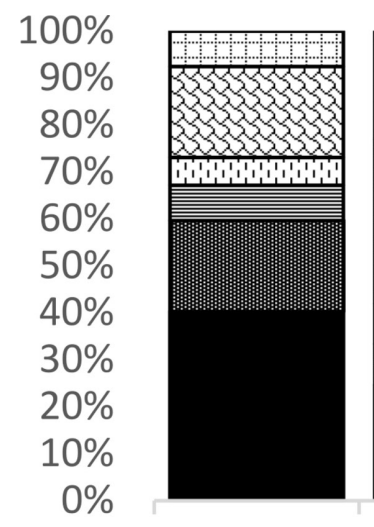

$\begin{array}{cc}\text { Bilateral } & \text { Bilateral } \\ \text { pre-op } & \text { post-op } \\ \text { (67eyes) } & \text { (69 eyes) }\end{array}$

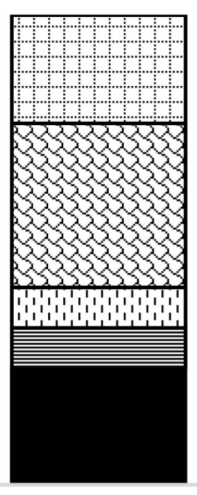$$
(69)
$$
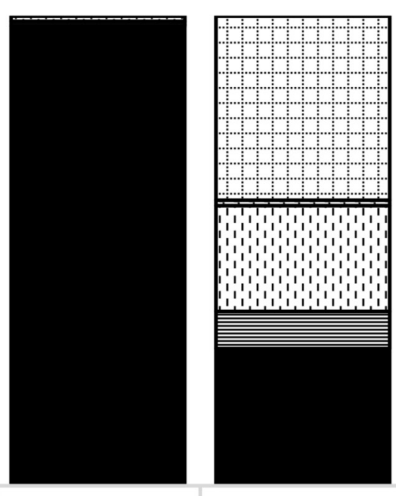

Traumatic Traumatic

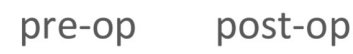

(87 eyes)
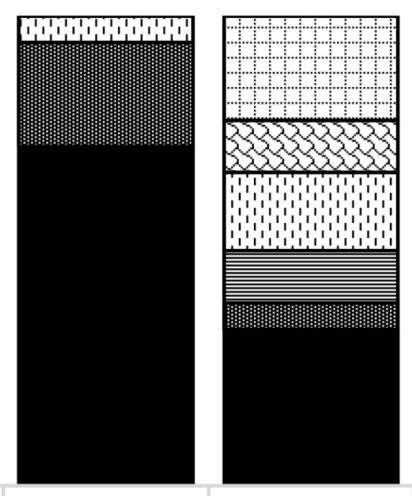

Unilateral

Non-

trauma

pre-op

(18 eyes)

\section{w

Figure 1 Per cent of eyes with each category of visual acuity (VA) before and after cataract surgery.

The interval between recognition of a problem in the eye and surgery ranged from 3 weeks to 156 months (median 25 months). Before surgery, $58 \%$ of these eyes were blind (VA $<3 / 60)$. Nystagmus was present in $24(35 \%)$ eyes and strabismus in 13 (19\%) eyes. The most common type of surgery under the age of 10 years was lens aspiration with posterior capsulotomy and AV (55\%). An IOL was implanted in $97 \%$ of operated eyes, mostly acrylic foldable IOLs (61\%) (table 2). The most common intraoperative complications were radial anterior capsulotomy tears (seven eyes, 10\%) and posterior capsular rupture with or without vitreous loss (five eyes, 7\%). The most common early postoperative complication was fibrinous uveitis (four eyes, 6\%) whereas visual axis opacification was the most common late postoperative complication which developed in 16 eyes (23\%). Surgical capsulotomy was required in 12 eyes and yttrium-aluminum-garnet (YAG) capsulotomy in two eyes. Glaucoma occurred in one eye which was controlled medically (table 3 ).

Follow-up after surgery ranged from day 1 to 33 months (median 2.8 months) and 41 (59\%) had at least three follow-up visits. Among 34 cases with bilateral cataract where better seeing eyes were analysed, 17 (50\%) children had follow-up for 3 months or more and 17 (50\%) had less than 3 months of follow-up.

\section{Visual outcome}

\section{Total operated eyes}

At their last recorded follow-up, among 45 eyes with quantitative Snellen acuity, $16 / 45$ eyes $(36 \%)$ had a presenting VA of 6/6-6/18, 6 eyes (13\%) had 6/24-6/60, and 23 eyes (51\%) had <6/60. In 24/69 (35\%) bilateral cataract eyes, a Snellen acuity could not be measured postoperatively, but the eye was able to fix and follow. If these eyes are categorised as having a good outcome, the number of bilateral cataract eyes achieving a good outcome is $40(58 \%)$, borderline outcome $6(8 \%)$ and poor outcome 23 (33\%). There was no statistically significant difference in postoperative VA between cataracts classified as developmental or congenital $(p=0.62)$.

\section{Better eye}

Among 34 children with both eyes operated, visual outcome in the better seeing eye was analysed: good outcome $(\geq 6 / 18$ or $\mathrm{FF})$ in $21(62 \%)$ of children, borderline outcome in $4(12 \%)$ and poor outcome in $9(26 \%)$.

\section{Unilateral non-traumatic cataract}

Before surgery, 94\% (17/18) of operated eyes were blind (VA $<3 / 60)$. Strabismus was present in seven eyes $(39 \%)$ and nystagmus in one eye. The delay to surgery ranged from 1 week to 91 months (median 18 months). The most common type of surgery in this group was lens aspiration with primary posterior capsulotomy (PPC) and AV in nine eyes (50\%) followed by lens aspiration without posterior capsulotomy. An IOL was implanted in $89 \%$ of eyes. The most common intraoperative complication was posterior capsular rupture with vitreous loss, which occurred in four eyes (22\%). Fibrinous uveitis and striate keratopathy occurred in two eyes each. Visual axis opacification was a rare $(6 \%)$ complication in this group (table 3 ).

Follow-up after surgery ranged from 1 day to 6 months (median 1 month), $14(77.8 \%)$ had less than a 3 -month follow-up, only $4(22.2 \%)$ had a follow-up of 3 or more months, and $56 \%$ of the eyes had at least three follow-up visits. At their last follow-up, four eyes (22\%) achieved 6/6-6/18, two eyes (11\%) FF, one eye (5.6\%) poor fixation, three eyes (17\%) 6/24-6/60, and eight eyes (44\%) had <6/60. In summary, six eyes (33\%) had good outcome, three eyes $(17 \%)$ had borderline outcome, and nine eyes $(50 \%)$ had poor visual outcome in this group. 
Table 2 Preoperative and intraoperative characteristics in operated eyes $(n=176)$

\begin{tabular}{|c|c|c|c|}
\hline & $\begin{array}{l}\text { Bilateral } \\
(\mathrm{n}=69), \mathrm{n}(\%)\end{array}$ & $\begin{array}{l}\text { Unilateral } \\
\text { non-traumatic } \\
(\mathrm{n}=18), \mathrm{n}(\%)\end{array}$ & $\begin{array}{l}\text { Unilateral } \\
\text { traumatic } \\
(\mathrm{n}=89), \mathrm{n}(\%)\end{array}$ \\
\hline \multicolumn{4}{|l|}{ Delay to surgery (months)* } \\
\hline $\begin{array}{l}\text { Median (minimum, } \\
\text { maximum) }\end{array}$ & $25(<1-156)$ & $18(<1-91)$ & 3 weeks $(<1-91)$ \\
\hline$\leq 6$ & $9(13.0)$ & $5(27.8)$ & $72(80.9)$ \\
\hline$>6-12$ & $7(10.1)$ & $1(5.6)$ & $2(2.2)$ \\
\hline $12-18$ & $18(26.1)$ & $3(16.6)$ & $8(9.0)$ \\
\hline$>18$ & $35(50.7)$ & $9(50.0)$ & $7(7.9)$ \\
\hline \multicolumn{4}{|l|}{ Preoperative presenting VA } \\
\hline$\geq 6 / 18$ or fixes and follows & $18(26.1)$ & - & - \\
\hline$<6 / 18-6 / 60$ & $4(5.8)$ & $1(5.6)$ & $1(1.1)$ \\
\hline $\begin{array}{l}<6 / 60 \text { or poor fixation } \\
\text { patternt }\end{array}$ & $47(68.1)$ & $17(94.4)$ & $88(98.9)$ \\
\hline \multicolumn{4}{|l|}{ Associated ocular comorbidity } \\
\hline Nystagmus & $24(34.8)$ & $1(5.6)$ & - \\
\hline Strabismus & $13(18.8)$ & $7(38.9)$ & $2(2.2)$ \\
\hline Corneal scar/opacity & - & - & $26(29.2)$ \\
\hline Posterior/anterior synechiae & - & - & $14(15.7)$ \\
\hline Corneal tear & - & - & $14(15.7)$ \\
\hline Iris sphincter tear & - & - & $3(3.4)$ \\
\hline Traumatic mydriasis & - & - & $3(3.4)$ \\
\hline Iridodialysis & - & - & $3(3.4)$ \\
\hline Dislocated/subluxated lens & - & $1(5.6)$ & $2(2.2)$ \\
\hline Corneal foreign body & - & - & $1(1.1)$ \\
\hline Retinal detachment & - & - & $1(1.1)$ \\
\hline \multicolumn{4}{|l|}{ Surgical procedure } \\
\hline $\mathrm{LA}+\mathrm{PPC}+\mathrm{AV}+\mathrm{PC} \mathrm{IOL}$ & $38(55.1)$ & $9(50.0)$ & $28(31.5)$ \\
\hline $\mathrm{LA}+\mathrm{PC} \mathrm{IOL}$ & $27(39.1)$ & $7(38.9)$ & $51(57.3)$ \\
\hline $\mathrm{LA}+\mathrm{PPC}+\mathrm{PC} \mathrm{IOL}$ & $2(2.9)$ & - & $1(1.1)$ \\
\hline Lensectomy with no IOL & $2(2.9)$ & $2(11.1)$ & $2(2.2)$ \\
\hline LA with no IOL & - & - & $6(6.7)$ \\
\hline $\mathrm{LA}+\mathrm{AC} \mathrm{IOL}$ & - & - & $1(1.1)$ \\
\hline \multicolumn{4}{|l|}{ Type of anterior capsulotomy } \\
\hline Vitrectorhexis & $51(73.9)$ & $13(72.2)$ & $44(49.4)$ \\
\hline V-capsulotomy & $16(23.2)$ & $5(27.8)$ & $44(49.4)$ \\
\hline $\mathrm{CCC}$ & $2(2.9)$ & - & $1(1.1)$ \\
\hline \multicolumn{4}{|l|}{ Type of IOL } \\
\hline Foldable & $42(60.9)$ & $9(50.0)$ & $35(39.3)$ \\
\hline PMMA & $25(36.2)$ & $7(38.9)$ & $45(50.6)$ \\
\hline No IOL & $2(2.9)$ & $2(11.1)$ & $9(10.1)$ \\
\hline \multicolumn{4}{|l|}{ Site of IOL implanted } \\
\hline In the bag & $55(79.7)$ & $7(38.9)$ & $36(40.4)$ \\
\hline Sulcus & $7(10.1)$ & $7(38.9)$ & $21(23.6)$ \\
\hline$A C$ & - & - & $1(1.1)$ \\
\hline No IOL & $2(2.9)$ & $2(11.1)$ & $9(10.1)$ \\
\hline Unknown & $5(7.2)$ & $2(11.1)$ & $22(24.7)$ \\
\hline
\end{tabular}

* Interval between recognition of cataract in the eye by caregivers and admission to hospital for surgery.

tFour eyes with undetermined vision (two in bilateral, two in unilateral traumatic) were included under $\mathrm{VA}<6 / 60$ or poor fixation category.

$\mathrm{AC} \mathrm{IOL}$, anterior chamber intraocular lens; $\mathrm{AV}$, anterior vitrectomy; CCC, continuous curvilinear capsulorhexis; $\mathrm{LA}$, lens aspiration; $\mathrm{PC}$, posterior capsule; $\mathrm{PC} I \mathrm{IOL}$, posterior chamber intraocular lens; PMMA, polymethylmethaacrylate; PPC, primary posterior capsulotomy; VA, visual acuity.

\section{Traumatic cataract}

A corneal tear repair was required at the time of cataract surgery in $13 / 89(14.7 \%)$ eyes. There was multiple other trauma-related ocular pathology including corneal scar or opacity in 26 eyes $(29.2 \%)$ and synechiae in 14 eyes $(15.7 \%)$. Preoperatively, 85 eyes $(95.5 \%)$ were blind (VA $<3 / 60)$. The most common surgical procedure was lens aspiration without vitrectomy in 51 eyes (57.3\%) and an IOL was not implanted in nine eyes $(10.1 \%)$ (table 2). The most common intraoperative complication was radial tear of anterior capsulotomy (10 eyes, $11.2 \%$ ) whereas the most frequent postoperative complications were fibrinous uveitis $(21.3 \%)$, corneal oedema $(18.0 \%)$ and visual axis opacification (14.6\%). Endophthalmitis occurred in three eyes (3.4\%) (table 3).

Follow-up after surgery ranged from 1 day to 12.4 months (median 1.2 month), 63 (70.8\%) children had less than a 3 -month follow-up, 26 (29.2\%) had a follow-up of 3 or more months, and $52.8 \%$ of the eyes had three or more follow-ups. After surgery, visual outcome was $6 / 6-6 / 18$ in 35 eyes (39\%), FF in 1 eye (1\%), 6/24-6/60 in 20 eyes (22\%) and $<6 / 60$ in 33 eyes $(37 \%)$.

\section{Factors associated with visual outcome Bilateral cases}

Regression analysis was carried out to determine the factors associated with poor visual outcome in the better seeing eye in the 34 children with bilateral cataract. The variables that were analysed are shown in table 4. In univariate and multivariate analysis, only the presence of ocular comorbidities, that is, strabismus or nystagmus, was significantly associated with poor outcome $(<6 / 60)$ than those without comorbidities (OR $10.63 ; 95 \%$ CI 1.22 to $92.34, \mathrm{p}=0.03$ ).

\section{Traumatic cases}

Only pre-existing trauma-related ocular comorbidity was significantly associated with poor outcome in univariate and multivariate analysis in traumatic cataracts $(\mathrm{OR}=6.23 ; 95 \%$ CI 2.01 to 19.25, $\mathrm{p}=0.001)$.

\section{DISCUSSION}

Over half of better seeing eyes in bilateral cases in our series achieved a VA $\geq 6 / 18$, or could fix and follow. It is difficult to compare our study with others because of the difficulties in recording VA in children, particularly in young children, and this is reflected in the large proportion of children with bilateral cataract in whom a Snellen acuity was not recorded. Children recorded as being able to fix and follow but without a Snellen VA were included in our good visual outcome category, but the imprecision of this acuity assessment is a limitation of our study. It has been suggested that younger children may have better results because they may have had less delay between the onset of cataract and treatment, or alternatively, that they may have worse results because of the onset of cataract at a younger age. The limitations of our data prevent us from definitively resolving this issue, and the classifications of cases as congenital or developmental were based on parental recall. We used presenting VA to assess visual outcome as best corrected VA was not recorded in $41.5 \%$ of eyes, implying that refraction may not have been undertaken at every visit. In addition, our intention was to include whether surgery was performed by a trained paediatric ophthalmologist or a qualified ophthalmologist experienced in adult surgery in the regression analysis but this was not possible as some cells contained no data.

Our results for good outcome in the better eye (62\%) among bilateral cases are comparable to studies in Tanzania $(62 \%),{ }^{10}$ Nepal and Northern India (43\%), ${ }^{4}$ Kenya (44\%), ${ }^{9}$ South India 
Table 3 Surgical complications, postoperative interventions and number of follow-up visits

\begin{tabular}{|c|c|c|c|}
\hline & $\begin{array}{l}\text { Bilateral } \\
\text { ( } n=69 \\
\text { eyes), } \\
n(\%)\end{array}$ & $\begin{array}{l}\text { Unilateral } \\
\text { non- } \\
\text { traumatic } \\
\text { ( } \mathrm{n}=18 \\
\text { eyes), } \\
\mathrm{n}(\%)\end{array}$ & $\begin{array}{l}\text { Unilateral } \\
\text { traumatic } \\
(\mathrm{n}=89 \text { eyes), } \\
\mathrm{n}(\%)\end{array}$ \\
\hline \multicolumn{4}{|l|}{ Intraoperative complication } \\
\hline Radial tear of capsulotomy & $7(10.1)$ & $1(5.6)$ & $10(11.2)$ \\
\hline PC rupture without vitreous loss & $5(7.2)$ & $2(11.3)$ & $1(1.1)$ \\
\hline Vitreous loss only & $1(1.4)$ & - & $1(1.1)$ \\
\hline PC rupture with vitreous loss & - & $4(22.2)$ & $4(4.5)$ \\
\hline \multicolumn{4}{|c|}{ Early postoperative complication (up to 4 weeks) } \\
\hline Fibrinous uveitis & $4(5.8)$ & $2(11.1)$ & $19(21.3)$ \\
\hline Striate keratopathy/corneal oedema & $2(2.9)$ & $2(11.1)$ & $16(18.0)$ \\
\hline Lens matter remnant & $1(1.4)$ & - & $7(7.9)$ \\
\hline Pupillary capture of IOL & $1(1.4)$ & $1(5.6)$ & - \\
\hline IOL decentration & - & - & $5(5.6)$ \\
\hline Endophthalmitis & - & - & $3(3.4)$ \\
\hline Iris prolapsed & - & - & $2(2.2)$ \\
\hline Shallow anterior chamber & - & - & $1(1.1)$ \\
\hline \multicolumn{4}{|c|}{ Late postoperative complication (after 4 weeks) } \\
\hline Visual axis opacification & $16(23.2)$ & $1(5.6)$ & $13(14.6)$ \\
\hline Pupillary capture of IOL & $4(5.8)$ & - & $2(2.2)$ \\
\hline Decentration of IOL & $2(2.9)$ & $1(5.6)$ & $1(1.1)$ \\
\hline Glaucoma & $1(1.4)$ & - & $1(1.1)$ \\
\hline Secondary membrane & - & - & $1(1.1)$ \\
\hline Vitreous haemorrhage & - & - & $1(1.1)$ \\
\hline \multicolumn{4}{|l|}{ Postoperative intervention } \\
\hline \multicolumn{4}{|l|}{ Surgical } \\
\hline $\begin{array}{l}\text { Surgical capsulotomy/ } \\
\text { membranectomy }\end{array}$ & $12(17.4)$ & $2(11.1)$ & $10(4.2)$ \\
\hline IOL repositioning & $5(7.2)$ & $2(11.1)$ & $3(3.4)$ \\
\hline YAG capsulotomy & $2(2.9)$ & - & $4(4.5)$ \\
\hline Excision of limbal conjunctival cyst & $1(1.4)$ & - & - \\
\hline Aspiration of lens matter & - & - & $2(2.2)$ \\
\hline IOL replacement & - & - & $1(1.1)$ \\
\hline \multicolumn{4}{|l|}{ Medical } \\
\hline Spectacle prescribed & $28(40.6)$ & $6(33.3)$ & $14(15.7)$ \\
\hline Patching therapy & $23(33.8)$ & $9(50.0)$ & $8(9.0)$ \\
\hline Systemic steroid & $2(2.9)$ & $1(5.6)$ & $12(13.5)$ \\
\hline \multicolumn{4}{|l|}{ Total number of follow-up visits } \\
\hline 1 & $8(11.6)$ & $2(11.1)$ & $16(18.0)$ \\
\hline 2 & $20(29.0)$ & $6(33.3)$ & $26(29.2)$ \\
\hline 3 & $20(29.0)$ & $5(27.8)$ & $28(31.5)$ \\
\hline 4 & $7(10.1)$ & $2(11.1)$ & $9(10.1)$ \\
\hline 5 & $4(5.8)$ & $2(11.1)$ & $5(5.6)$ \\
\hline 6 & $8(11.6)$ & $1(5.6)$ & $2(2.2)$ \\
\hline 7 & $2(2.9)$ & - & $3(3.4)$ \\
\hline
\end{tabular}

$\mathrm{IOL}$, intraocular lens; $\mathrm{PC}$, posterior capsule; $\mathrm{YAG}$, yttrium-aluminum-garnet.

$(39.5 \%),{ }^{17}$ UK $(40.6 \%)^{18}$ and USA (46.6\%), ${ }^{19}$ but much better than in studies from Zambia $(29.7 \%)^{13}$ and South Africa $(24.7 \%) .{ }^{14}$ Good visual outcome was achieved more often in bilateral cases compared with unilateral non-traumatic cases.

Only $33 \%$ of eyes in unilateral non-traumatic cataract achieved good outcome $(\geq 6 / 18)$ and with half of the eyes having a poor visual outcome $(<6 / 60)$ with median follow-up period of 1 month. This finding is similar to the study in India where best corrected VA was $6 / 18$ or better in $25 \%$ and $<6 / 60$ in $66.7 \%$ of unilateral congenital and developmental cataracts at mean follow-up of 4.4 years. ${ }^{20}$ The poor outcome in a significant number of eyes in unilateral cases can be explained by deep deprivational amblyopia.

Thirty-five eyes (39\%) with traumatic cataract had a VA of $6 / 18$ or better. This is slightly lower than in studies in Zambia $(68 \%),{ }^{13}$ and the previous study in Southern Ethiopia (64.7\%). ${ }^{21}$

There was a substantial improvement in VA for each type of cataract, with the greatest improvement being in traumatic cases, no doubt reflecting the lower risk of amblyopia in children who developed cataract later in childhood. The finding of a relatively good acuity in a few children with non-traumatic cataract may be due to undetected trauma, or later onset of cataract.

In this study, the mean age at surgery was 5.8 years and 7 years in bilateral and unilateral non-traumatic cases, respectively. Children with traumatic cataract were older (mean 9.8 years). This is similar to the findings in the previous study in Ethiopia (mean 7.1 years) ${ }^{15}$ and other studies in low/middle-income countries. ${ }^{310-12}$ However, the age at surgery for non-traumatic cases in our study was higher than a report from developed countries. ${ }^{18}$ A study from Kenya also showed a younger age at surgery compared with our study. ${ }^{9}$

To achieve better visual outcome in children, earlier cataract surgery is recommended. However, the finding in this study showed late presentation with a median delay to surgery of 25 and 18 months in bilateral and unilateral non-traumatic cases, respectively. This delay will result in significant deprivational amblyopia, reflected in the high rates of nystagmus and strabismus which were associated with poorer outcomes. A mean delay of almost 3 years between first recognition of an abnormality by parents/caregivers and surgery for congenital and developmental cataract was reported in a study from Tanzania. ${ }^{22}$ Delay in presentation was associated with developmental cataract, living far from the hospital and low socioeducational status of the mother. Complex interactions between sociocultural barriers at family and community levels as well as socio-organisational barriers within the healthcare system also contributed to delay in presentation. ${ }^{23}$

However, our study showed that delay between presentation and surgery did not greatly affect outcomes. This is in line with two studies from India ${ }^{2425}$ but unlike results from China. ${ }^{26}$

The high proportion of traumatic cataract in this series is worth noting, being higher than studies from Southern Ethiopia (36.3\%), ${ }^{15}$ Madagascar (25.6\%) ${ }^{11}$ and Nepal (23.9\%). ${ }^{3}$ In contrast, in high-income settings, trauma accounts for only 10\%-29\% of cases. $^{27}$ The high proportion of traumatic cataract in our series may be because in Ethiopia children are often involved in agriculture, and the sudden pain and loss of vision will stimulate different health-seeking behaviour by parents compared with that for children with long-standing, painless loss of vision for which parents may have no explanation or attribute to spiritual causes. The finding from the recent key informant study that bilateral cataract was the leading cause of blindness in children indicates the need for active community-based case finding with referral for assessment, surgery and counselling. ${ }^{8}$

In this series, follow-up after cataract surgery was inadequate. Before surgery, parents need to be counselled that surgery is only the first stage, and that postoperative visual rehabilitation including amblyopia therapy, correction of refractive error and low vision therapy are all important. Barriers to follow-up have been reported from Tanzania and included being a girl with bilateral cataract, poorly educated mothers, a large number of siblings and delay in initial presentation for surgery. ${ }^{28}$ Multiple strategies were used to improve follow-up, including reimbursement of transport costs, a dedicated childhood blindness coordinator, tracking children 
Table 4 Factors associated with poor visual outcome in children with bilateral developmental or congenital cataract based on the better seeing eye $(n=34)$

\begin{tabular}{|c|c|c|c|c|c|c|}
\hline & $\begin{array}{l}\text { Good or borderline } \\
\text { outcome }(\geq 6 / 60 / \mathrm{FF})\end{array}$ & $\begin{array}{l}\text { Poor outcome } \\
(<6 / 60)\end{array}$ & Crude OR $(95 \% \mathrm{CI})$ & $P$ values & Adjusted OR (95\% Cl) & $P$ values \\
\hline $\begin{array}{l}\text { Age at surgery (year) } \\
\text { Mean=5.7, SD=4.6 }\end{array}$ & - & - & 1.01 (0.85 to 1.19$)$ & 0.94 & - & - \\
\hline Male & 13 & 6 & $0.93(0.24$ to 3.50$)$ & 0.91 & - & - \\
\hline Female & 12 & 3 & Reference & & & \\
\hline Congenital & 15 & 4 & Reference & & & \\
\hline $\begin{array}{l}\text { Delay to surgery (month)* } \\
\text { Mean }=3.4, S D=3.4\end{array}$ & - & - & 1.02 (0.99 to 1.05$)$ & 0.09 & 1.03 (0.99 to 1.07 ) & 0.09 \\
\hline \multicolumn{7}{|l|}{$\begin{array}{l}\text { Ocular comorbidities (nystagmus/ } \\
\text { strabismus) }\end{array}$} \\
\hline Present & 6 & 7 & 11.08 (1.80 to 68.40$)$ & 0.01 & 10.63 (1.22 to 92.34$)$ & 0.03 \\
\hline Performed & 13 & 8 & Reference & & Reference & \\
\hline \multicolumn{7}{|l|}{ Intraoperative complications } \\
\hline Present & 5 & 1 & 0.07 (0.002 to 1.99$)$ & 0.55 & - & - \\
\hline Absent & 20 & 8 & Reference & & & \\
\hline \multicolumn{7}{|l|}{ Postoperative complications } \\
\hline Present & 10 & 1 & 0.19 (0.02 to 1.74$)$ & 0.14 & $0.42(0.03$ to 5.75$)$ & \\
\hline Absent & 15 & 8 & Reference & & Reference & \\
\hline $\begin{array}{l}\text { Duration of follow-up (months) } \\
\text { Mean }=5.8, S D=9.2\end{array}$ & & & 0.80 (0.55 to 1.16$)$ & 0.24 & - & - \\
\hline
\end{tabular}

*Indicates interval between recognition of cataract in the eye by caregivers and admission to hospital for surgery.

$\mathrm{FF}$, fix and follow; PPC, primary posterior capsulotomy.

after surgery, good counselling of parents and use of cellphone reminders. $^{29}$

In this study, limitations included poor documentation of relevant details in medical records, lack of standard definitions, methods of measuring VA and difficulty in distinguishing congenital from developmental cataract. Selection bias is also likely, as severely injured eyes might have developed endophthalmitis or not be operated on if the prognosis was poor. VA findings have to be interpreted cautiously, given the relatively short follow-up. Electronic medical records may improve documentation.

\section{CONCLUSIONS}

The short-term visual outcome after cataract surgery was fair as the majority achieved a VA of 6/60 or better. There was a significant delay in presentation particularly in non-traumatic cases. The presence of nystagmus/strabismus in bilateral cases and the trauma-related complications in traumatic cases were predictors of poor visual outcome. To address cataract blindness, active case finding combined with counselling parents and clear referral pathways are needed. Surgery should be undertaken by a paediatric ophthalmologist in a fully equipped unit, with trained support staff, and multiple strategies are likely to be required to improve follow-up after surgery. Prospective studies are being set up to address some of the limitations identified in this case series.

Acknowledgements We would like to thank Orbis international-Ethiopia for their kind support in establishing child eye health tertiary facility in Gondar University Hospital and British Council for the Prevention of Blindness for supporting our research as part of research mentorship award grant.
Contributors MA, SYM and ST conceived the study. MA collected the data. SYM did the statistical analysis of the data. MA, GW and CEG further analysed the data. All the authors contributed to the manuscript and approved the final draft for submission.

Funding MA was supported by a mentoring grant by the British Council for the Prevention of Blindness, UK

Competing interests None declared.

Patient consent Not required.

Ethical approval The protocol of the study was approved by the Institutional Review Board of the University of Gondar.

Provenance and peer review Not commissioned; externally peer reviewed.

Data sharing statement No additional data are available.

(c) Article author(s) (or their employer(s) unless otherwise stated in the text of the article) 2019. All rights reserved. No commercial use is permitted unless otherwise expressly granted.

\section{REFERENCES}

1 Courtright P. Childhood cataract in sub-Saharan Africa. Saudi J Ophthalmol 2012;26:3-6.

2 Gilbert CE, Lepvrier-Chomette N. Gender inequalities in surgery for bilateral cataract among children in low-income countries: a systematic review. Ophthalmology 2016;123:1245-51.

3 Wilson ME, Hennig A, Trivedi RH, et al. Clinical characteristics and early postoperative outcomes of pediatric cataract surgery with IOL implantation from Lahan, Nepal. J Pediatr Ophthalmol Strabismus 2011:48:286-91.

4 Hennig A, Schroeder B, Gilbert C. Bilateral pediatric cataract surgery: outcomes of 390 children from Nepal and Northern India. J Pediatr Ophthalmol Strabismus 2013;50:312-9.

5 Berhane Y, Worku A, Bejiga A. Prevalence and causes of blindness and low vision in Ethiopia. Ethiop J Health Dev 2007;21:204-10. 
6 Kello $A B$, Gilbert $C$. Causes of severe visual impairment and blindness in children in schools for the blind in Ethiopia. Br J Ophthalmol 2003;87:526-30.

7 Asferaw M, Woodruff G, Gilbert C. Causes of severe visual impairment and blindness in students in schools for the blind in Northwest Ethiopia. BMJ Glob Health 2017;2:e000264.

8 Demissie BS, Solomon AW. Magnitude and causes of childhood blindness and severe visual impairment in Sekoru District, Southwest Ethiopia: a survey using the key informant method. Trans R Soc Trop Med Hyg 2011;105:507-11.

9 Yorston $D$, Wood M, Foster $A$. Results of cataract surgery in young children in East Africa. Br J Ophthalmol 2001;85:267-71.

10 Bowman RJ, Kabiru J, Negretti G, et al. Outcomes of bilateral cataract surgery in Tanzanian children. Ophthalmology 2007;114:2287-92.

11 Randrianotahina HC, Nkumbe HE. Pediatric cataract surgery in Madagascar. Niger J Clin Pract 2014;17:14-17.

12 Umar MM, Abubakar A, Achi I, et al. Pediatric cataract surgery in National Eye Centre Kaduna, Nigeria: outcome and challenges. Middle East Afr J Ophthalmol 2015;22:92-6.

13 Mboni C, Gogate PM, Phiri A, et al. Outcomes of pediatric cataract surgery in the copperbelt province of Zambia. J Pediatr Ophthalmol Strabismus 2016:53:311-7.

14 Gogate P, Parbhoo D, Ramson P, et al. Surgery for sight: outcomes of congenital and developmental cataracts operated in Durban, South Africa. Eye 2016;30:406-12.

15 Tomkins O, Ben-Zion I, Moore DB, et al. Outcomes of pediatric cataract surgery at a tertiary care center in rural southern Ethiopia. Arch Ophthalmol 2011;129:1293-7.

16 Wilson ME, Pandey SK, Thakur J. Paediatric cataract blindness in the developing world: surgical techniques and intraocular lenses in the new millennium. Br J Ophthalmol 2003:87:14-19.

17 Khanna RC, Foster A, Krishnaiah S, et al. Visual outcomes of bilateral congenital and developmental cataracts in young children in south India and causes of poor outcome. Indian J Ophthalmol 2013;61:65-70.
18 Chak M, Wade A, Rahi JS. British Congenital Cataract Interest Group. Long-term visual acuity and its predictors after surgery for congenital cataract: findings of the British congenital cataract study. Invest Ophthalmol Vis Sci 2006;47:4262-9.

19 Ledoux DM, Trivedi RH, Wilson ME, et al. Pediatric cataract extraction with intraocular lens implantation: visual acuity outcome when measured at age four years and older. J Aapos 2007;11:218-24

20 Gogate P, Patil S, Kulkarni A, et al. Unilateral congenital and developmental cataracts in children in India: How useful were long-term outcomes of surgery? Miraj pediatric cataract study 4. Asia Pac J Ophthalmol 2015;4:376-80.

21 Kinori M, Tomkins-Netzer 0, Wygnanski-Jaffe T, et al. Traumatic pediatric cataract in southern Ethiopia - results of 49 cases. J Aapos 2013:17:512-5.

22 Mwende J, Bronsard A, Mosha M, et al. Delay in presentation to hospital for surgery for congenital and developmental cataract in Tanzania. Br J Ophthalmol 2005;89:1478-82.

23 Bronsard A, Geneau R, Shirima S, et al. Why are children brought late for cataract surgery? Qualitative findings from Tanzania. Ophthalmic Epidemiol 2008;15:383-8.

24 Gogate P, Khandekar R, Shrishrimal M, et al. Delayed presentation of cataracts in children: are they worth operating upon? Ophthalmic Epidemiol 2010;17:25-33.

25 Gogate PM, Sahasrabudhe M, Shah M, et al. Long term outcomes of bilateral congenital and developmental cataracts operated in Maharashtra, India. Miraj pediatric cataract study III. Indian J Ophthalmol 2014;62:186-95.

26 You C, Wu X, Zhang Y, et al. Visual impairment and delay in presentation for surgery in Chinese pediatric patients with cataract. Ophthalmology 2011;118:17-23.

27 Wilson ME Jr, Trivedi RH, Pandey SK. Traumatic cataracts in children. In: Wilson ME Jr, Trivedi RH, Pandey SK, eds. Pediatric cataract surgery. Philadelphia, PA: Lippincott Williams \& Wilkins, 2005.

28 Eriksen JR, Bronsard A, Mosha M, et al. Predictors of poor follow-up in children that had cataract surgery. Ophthalmic Epidemiol 2006:13:237-43.

29 Kishiki E, Shirima S, Lewallen S, et al. Improving postoperative follow-up of children receiving surgery for congenital or developmental cataracts in Africa. J Aapos 2009;13:280-2. 